\title{
THE LEAN SIX SIGMA IN A PUBLIC HOSPITAL
}

\author{
Kenza Tadlaoui* Anas Chafi Abdelali Ennadi \\ Université Sidi Mohamed Ben Abdellah, Faculté des sciences et techniques de Fès, \\ Laboratoire des techniques industrielles, Maroc
}

The hospital can be likened to an industrial enterprise with a high level of security expected. Indeed, the patient has particularities: it is a living being brought to the hospital in an uncontrolled manner and difficult to regulate or anticipate accurately. In addition, the constraint in the public hospital is financial: It is to treat a maximum of patients, the best possible, with limited financial resources. Despite this constraint, patient demands are high in terms of quality of treatment and medical innovations. Hence the interest of using the methods used in the industrial management of high security environments namely Lean management to adequately meet the constraints of economic and societal efficiency, flexibility and security imposed by the hospital stakeholders. In this article, we will try to define the concept of Lean six sigma in care institutions, then we will describe the methodology adopted that of the DMAIC method and in the end to implement the first 3 steps of this method. in a public hospital.

Key words: DMAIC, SCOR, ARIS, Performance indicator, SWOT

\section{INTRODUCTION}

Like an industrial enterprise, the current hospital has the following characteristics, whatever its status or location [01]:

- It consists of a set of scarce and limited resources, of which it must justify an efficient use;

- It must coordinate management of multiple flows (patient flows, flows of medicines and treatments, information flows, financial flows) in a permanent concern of multiple efficiency: to guarantee the good care of the right patient at the right moment with sufficient information, medicines and adequate infrastructure, all at the lowest cost.

- It must motivate the main critical resource, all collaborators (medical, nursing, support technician, management support body), by continuously solving the daily challenges of good interpersonal communication and communication and a perfect coordination with the patient's expectations.

- It must deploy a clear, consistent and effective strategy on a daily basis with regard to the expectations and objectives of the organization's stakeholders and the opportunities offered by its competitive and technological environment.

As a result, the hospital can be likened to an industrial enterprise with a high level of security expected. Indeed, the patient presents particularities: it is a living being brought to the hospital in an uncontrolled and difficult to regulate or anticipate accurately. Thus, the constraint in the public hospital is financial (state budget). It is a question of treating as many patients as possible, with the best possible financial resources. Despite this constraint, patient demands are high in terms of quality of treatment and medical innovations [02].
Hence the interest of using the methods used in the industrial management of high security environments namely Lean management to adequately meet the constraints of economic and societal efficiency, flexibility and security imposed by the hospital stakeholders.

In this article, we will try to define the concept of Lean six sigma in care institutions, then we will describe the methodology adopted that of the DMAIC method and in the end to implement the first 3 steps of this method. in a public hospital.

\section{LEAN SIX SIGMA IN CARE INSTITUTIONS}

First, service companies, such as those providing health care, would benefit from adopting the Lean Six sigma for the following three reasons [03]:

1. Processes in services are generally slow, so costly,

2. Processes in services are slow because there is far too much work going on, which is often too complex

3. In any slow process, $80 \%$ of the waiting time is attributable to less than $20 \%$ of the activities.

Lean Six Sigma tools and methods can be directly applied, or with minor adjustments, to health care as they are in manufacturing [04], [05] and [06]. It is therefore common to find in the literature positive results of the application of Lean Six sigma in health care [07] and [08].

\section{METHODOLOGY ADOPTED: THE DMAIC METHOD}

The best-known method of Lean Six Sigma is DMAIC ("Define, Measure, Analyze, Improve, Control," meaning "define, measure, analyze, improve and control"). This method is a problem-solving approach that combines qualitative and quantitative tools to improve the processes in place [06] and [09]. These tools help to define the scope and objectives of the project (to define), to outline potential problems hindering the processes in place

* Université Sidi Mohamed Ben Abdellah, Faculté des sciences et techniques de Fès, B.P. 2202 - Route d'Imouzzer, 
(to measure), and then to identify and analyze the root causes of the time required to grant leave (to analyze), undertake the improvement and control stages [06].

It has been successfully used in many care hospital settings and has reduced the length of hospital stays for almost half of trauma patients [10].

In this paper, we will focus on the first 3 steps of DMAIC method namely: Define, Measure and Analyze.

Table 1 explains our adopted methodology.

Table 1: Methodological steps of the DMAIC method

\begin{tabular}{|c|c|}
\hline Steps DMAIC & Actions to be completed \\
\hline to define & $\begin{array}{c}\text {-Delimit the scope of the study - } \\
\text { Data collection plan } \\
\text {-Define the performance indicators to } \\
\text { be measured }\end{array}$ \\
\hline to measure & $\begin{array}{r}\text {-Model the processes } \\
\text {-Calculating the indicators }\end{array}$ \\
\hline to analyze & Analyze failures \\
\hline
\end{tabular}

\section{IMPLEMENTATION OF THE DMAIC METHOD}

\section{Step 1: DEFINE}

\section{THE SCOPE OF THE STUDY}

This is a descriptive, exploratory retrospective mixed study. It took place over a 4-month period from February to April 2016, with a two-month data collection period. The appropriate quote is the case study, unique case type hospital Sidi Lahcen with nested analysis levels, this quote allows us to analyze in depth.

\section{Presentation of the PHC}

The Sidi Lahcen Hospital is a prefectural hospital center of Skhirat-Temara, was inaugurated on May 20, 1995. It was erected in autonomous state service (ASS) on the $01 / 07 / 1998$, it is the only hospital of the prefecture. It is part of the Skhirat-Temara delegation and is aimed at a population of more than 539,000 inhabitants for an operating budget of around $8,000,000 \mathrm{DH}$. It is a suburban hospital with a litter capacity of 59 beds is 1 bed / 9135 inhabitants

\section{DATA COLLECTION PLAN}

The data was collected through five methods: document consultation, observation, semi-structured interviews, focus group and questionnaire. The questionnaire was first pre-tested and then rectified.

\section{The consultation of documents}

Determined the proportion of the pharmaceutical budget in the hospital's operating budget to determine the amount of resources allocated to the purchase of pharmaceuticals. Consultation of the management tools: the delivery notes, the inventory sheets, the reception notes, the order forms and the inventory were made in order to:

- Recognize the availability and correct use of management tools;

- Calculate and analyze some important management data and indicators: the expiry rate of pharmaceutical products (PP), the duration of stockouts, and the percentage of leftovers to be delivered for pharmaceutical products (PP).

\section{Observation using a grid}

It was conducted at the pharmacy of the hospital to see the compliance of the latter with the standards of storage, organization and conservation of PP. We also checked the availability and qualification of staff of the hospital pharmacy employed in their management.

\section{Semi structured interviews}

Semi-structured interviews were used to identify and describe the PP circuit. They were carried out on the basis of a personal interview guide, with the chiefs of services, the pharmacist and head of administrative and economic service.

\section{The question sheet}

The questionnaire was administered to the nurse heads of services to assess the management mode of PP at the level of care services.

\section{The group focus}

We have been able to identify the causes of stock outs of pharmaceuticals and suggest suggestions for improving the availability of pharmaceuticals.

\section{DEFINITION OF PERFORMANCE INDICATORS}

The availability of pharmaceutical products is the result of the performance of the supply system but also of the suppliers and recipients who place their orders [11]. Thus the performance of the supply system is conditioned by a good stock management, and an optimization in the order, in other words, the efficient supply is that which makes it possible to buy the right product, in necessary quantity, the right moment.

We refer to the models of indicators proposed by the French Society of Clinical Pharmacy in 2015. This organization was asked to develop and validate activity indicators in the field of hospital pharmacy.

We focus on the indicators of the purchase and logistics and distinguish in the Table 2 the indicators of the production, the quality as well as the tasks and the designations: 
Table 2: Production Indicators and Quality of Drug Logistics

\begin{tabular}{|c|c|c|c|}
\hline Indicator type & Field of activity & Task & Indicator \\
\hline Production & $\begin{array}{l}\text { Replenishment of a } \\
\text { service cabinet }\end{array}$ & $\begin{array}{l}\text { Replenish several } \\
\text { times a week }\end{array}$ & $\begin{array}{l}\text { Number of refill lines by } \\
\text { Pharmacy staff } \\
\text { for Internal Use }\end{array}$ \\
\hline \multirow{4}{*}{ Quality } & $\begin{array}{c}\text { Inventory } \\
\text { management }\end{array}$ & Inventory a stock & $\begin{array}{c}\text { Number of inventoried } \\
\text { reference lines / Number } \\
\text { of references stored at the } \\
\text { pharmacy }\end{array}$ \\
\hline & $\begin{array}{c}\text { Inventory } \\
\text { management }\end{array}$ & Reliability of stocks. & $\begin{array}{c}\% \text { of references to inventory } \\
\text { difference }\end{array}$ \\
\hline & $\begin{array}{l}\text { Inventory } \\
\text { management }\end{array}$ & $\begin{array}{l}\text { Track the obsolescence } \\
\text { of the stock } \\
=\text { Expiration rate }\end{array}$ & $\begin{array}{c}\% \text { of expired } \\
=\text { Value of expired over a } \\
\text { year } / \text { Value of the stock at } \\
\text { the end of the year }\end{array}$ \\
\hline & $\begin{array}{l}\text { Global delivery of } \\
\text { health products }\end{array}$ & $\begin{array}{c}\text { Evaluate Service Delivery } \\
=\text { Service Level of the } \\
\text { Supply Division }\end{array}$ & $\begin{array}{l}\text { Number of lines served / } \\
\text { Number of lines requested }\end{array}$ \\
\hline
\end{tabular}

It is considered that it is necessary to add an important indicator that of the rupture rate which is equal to (Sum of unmet drug requests / total amount of drug requests);

\section{Step 2: MEASURE}

First, before modeling pharmaceutical management processes, we will begin with the presentation of Pharmaceutical Logistics Chain within the Hospital (PLCH) Sidi Lahcen.

PP supply is carried out according to two main processes "Figure 1":

\section{Provision of Managed PP on Nomenclature:}

This procurement is done by the SD and comprises several successive phases:

- The notification made by the Directorate of Planning and Financial Resources (DPFR) of the appropriations that delimit the purchasing power of the SD for the year $\mathrm{n}+1$.

- The sending of the order form PP composed of the National List of Essential Medicines (NLEM) and the National List of Medical Devices by the DA at the Hospital.

- The qualitative selection of PF by a committee of drugs and medical devices made from the national list of essential drugs (NLED) and the national list of medical devices (NLMD). This committee is composed as follows:

*The director of the hospital and the pharmacist;

*The head of pole of medical affairs

${ }^{*}$ Council of dentists pharmacists

*The heads of hospital services
- The quantification of pharmaceutical needs is done at the level of each service, estimated using the annual consumption method. It is not based on treatment regimens. A meeting is organized between the pharmacist and the department head to validate the order. Then, the pharmacist regroups the needs of the services and readjust the quantities to be ordered according to the remains to be delivered from previous years and the available stock, then recalculates the total amount and returns the order form of the PP duly informed to the SD.

- The acquisition of PP is done exclusively by the SD. For example, PP are purchased from national suppliers (drug laboratories and medical device suppliers), except for the purchase of vaccines at UNICEF. The acquisition is made by launching tenders in accordance with the provisions of decree no. 2-12-349 of 08 joumada I 1434 (20 March 2013) relating to public procurement.

- Receipt and storage by the SD of the products ordered from the suppliers. The SD then ensures the partial delivery of the PP ordered by the hospital according to a schedule.

- The receipt and storage of PP by the hospital in 2 premises, one for drugs and one for medical devices.

- The distribution of pharmaceutical products to care units according to three distribution modes:

- The global distribution: This is the most used at the hospital. The products are delivered on the basis of a PP delivery note drawn from a voucher book. The products are then stored in wardrobes and delivered as and when to the nursing staff who administers them following a medical prescription. The vouchers 
are of two types: The monthly delivery slip that allows the service to order the products it needs for a period of one month. Delivery notes duly signed by the heads of services and the head nurses must reach the pharmacy at least 48 hours in advance to allow the pharmacy to prepare the delivery in time and avoid delays and delivery expectations. Orders are not systematically analyzed by the pharmacist. The determination of the quantities to be delivered is made according to the available stock. The pharmacy does not impose a limit, in quantity or value, for the orders of the services. The voucher for supplement or for an urgent order allows to order the drugs which the service needs and which are not available any more.

- The individual dispensing to hospitalized patients for expensive drugs. This type of dispensing consists in delivering the Drugs to a patient on presentation of a prescription bearing the name, the admission number, the product designation, the dosage, the duration of treatment, dated and signed by the attending physician.

- Prescription by registered prescription of implantable medical devices

- The dispensing by prescription of methotrexate to the Ramed patients followed by the rheumatologists of the hospital but not hospitalized.

\section{Supply of non-nomenclature PP:}

This purchase is made directly from wholesalers either by:

- The launch of the order forms for the non-nomenclature PP at break-up and close-break, or the PP which are also at the SD level;

- or through the launch of the call for tenders for non-nomenclature medical devices or the PP out of the SD.

\section{PROCESS MODELING BY SCOR AND ARIS}

\section{Modeling by SCOR}

Our approach is a hybrid approach that combines the SCOR and ARIS models. The choice of the SCOR model is justified by the fact that it allows:

- -to represent any type of company, a macro identification of the key processes of the supply chain,

- -develop a dashboard of each process activity.

The ARIS formalism is a concise and efficient simple formalism to model in detail the information flow of the supply chain.

The proposed model represents an integration of the ARIS model into the SCOR model.

From the analysis of the overall scheme described in Figure 1, it turned out that the modeling of the Pharmaceutical Logistics $(\mathrm{PL})$ goes beyond the limits of pharmacy. It requires the involvement upstream of certain actors from the Ministry of Public Health, who play the role of internal suppliers and planners. These are the Directorate of Planning and Financial Resources (DPFR) and the Supply Division (SD). Downstream, care units are internal clients that use pharmaceuticals. The patient is, in our case, assimilated to the final consumer.

\section{Modeling by the ARIS tool}

We modeled the globalized and nominative PP distribution process at Sidi Lahcen Hospital using the ArisExpress tool. Indeed, these processes include the main tasks of the hospital pharmacy (logistic vision), in order to compare the new organization with the old one

\section{Organizational chart}

The aim is to formalize the organization chart corresponding to the functions of the PLCH. The goal is to isolate the actors who intervene during this chain. The flowchart "Figure 3 "shows that the PLCH is the business of four organizational units namely: the hospital pharmacy, the care unit, the administrative and economic affairs and the management of the hospital.

\section{Value Chain}

The value chain (VC) is composed of a set of processes (represented by arrows) connected by precedence or superiority relationships. "Figure 4" presents the VC of the pharmaceutical supply chain according to the adapted SCOR model.

\section{Event Process Chain}

The event process chain (EPC) is a diagram detailing a process (an element of a value chain). EPC is a set of events and functions that follow a specified logical flow through the use of logical operators, such as OR, AND, and XOR. In this framework, the EPC diagram allows us to describe processes by showing how events trigger activities. We also included the information flows (incoming and outgoing data), as well as the actors in each step of the PP distribution process to care units within Sidi Lahcen Hospital "Figure 5". 


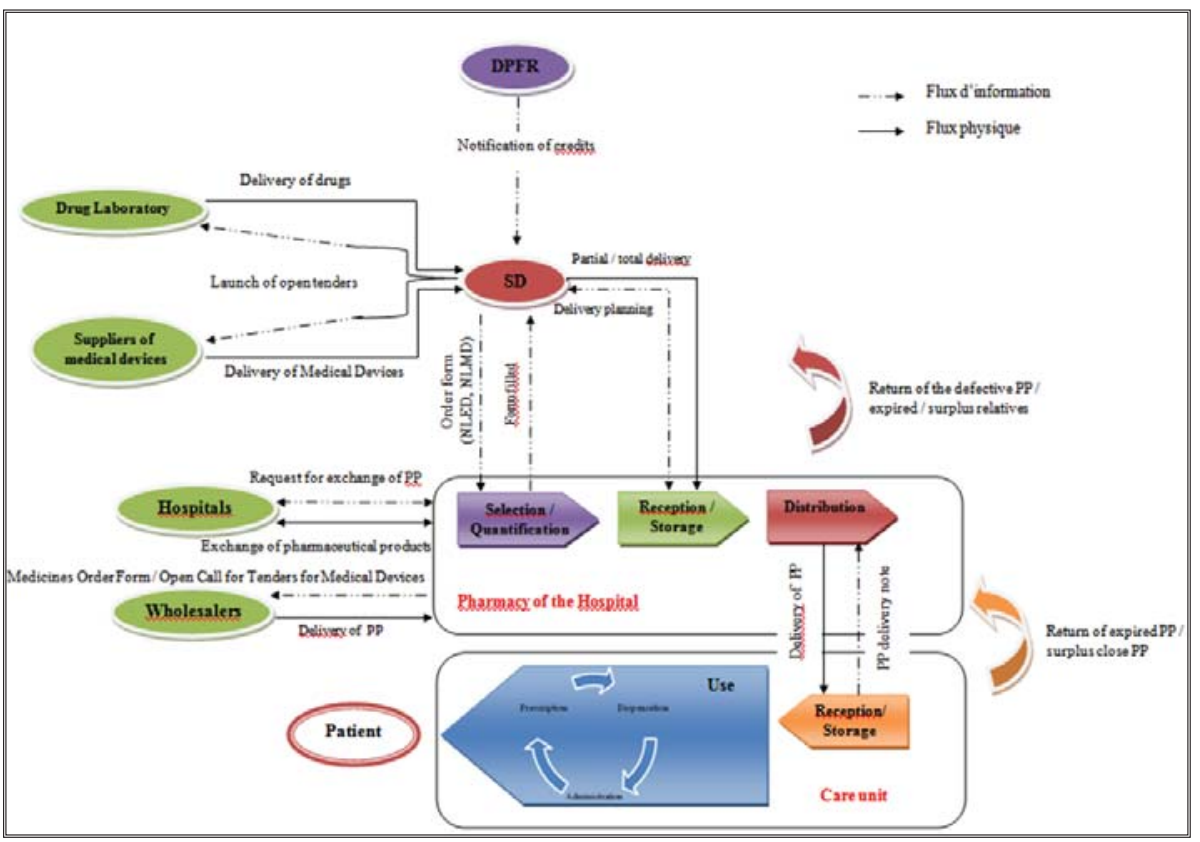

Figure 1: Overall diagram of PP supply and distribution flows within the Public Hospital [12]
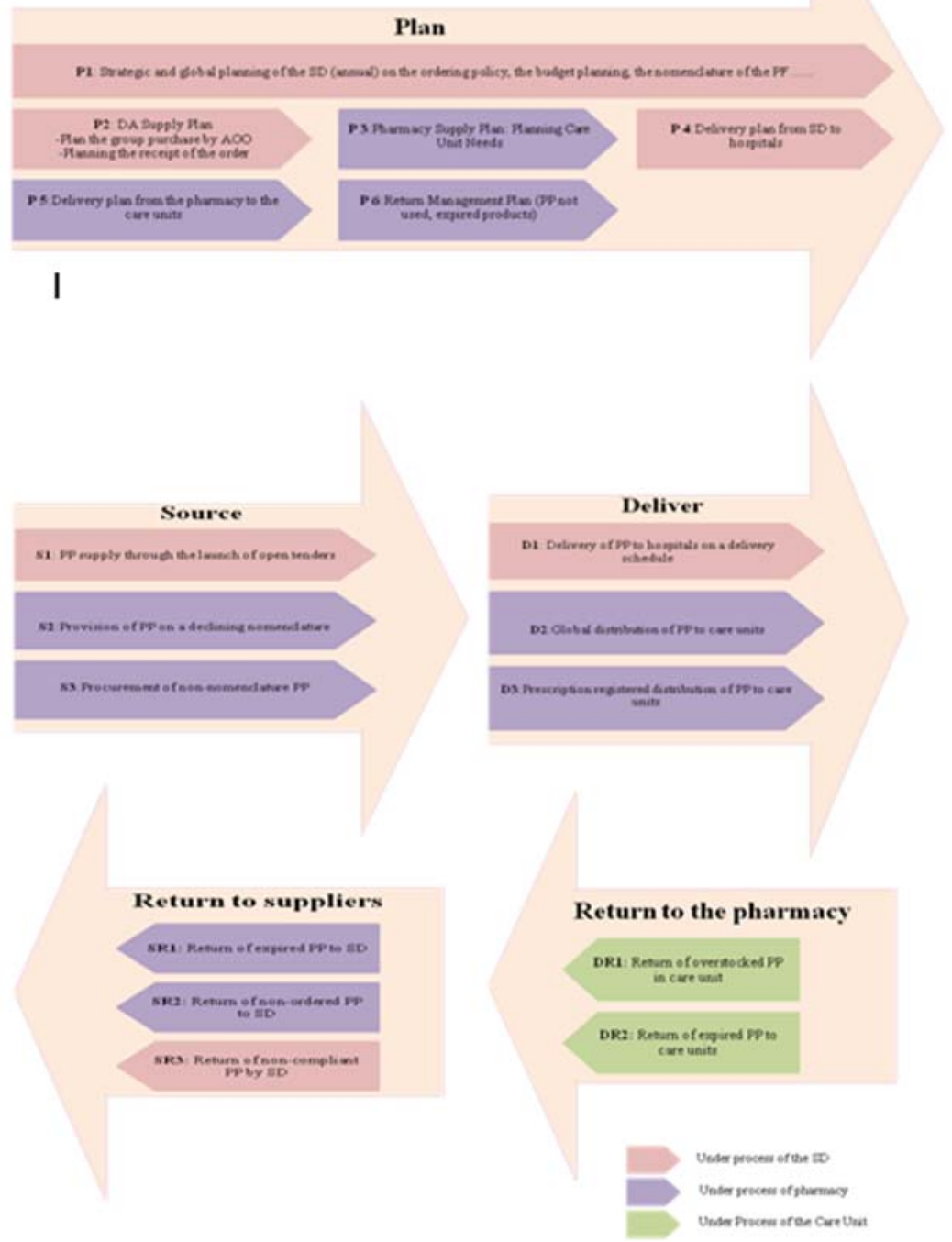

Figure 2: Process Identification (Level 2: Process Category) 


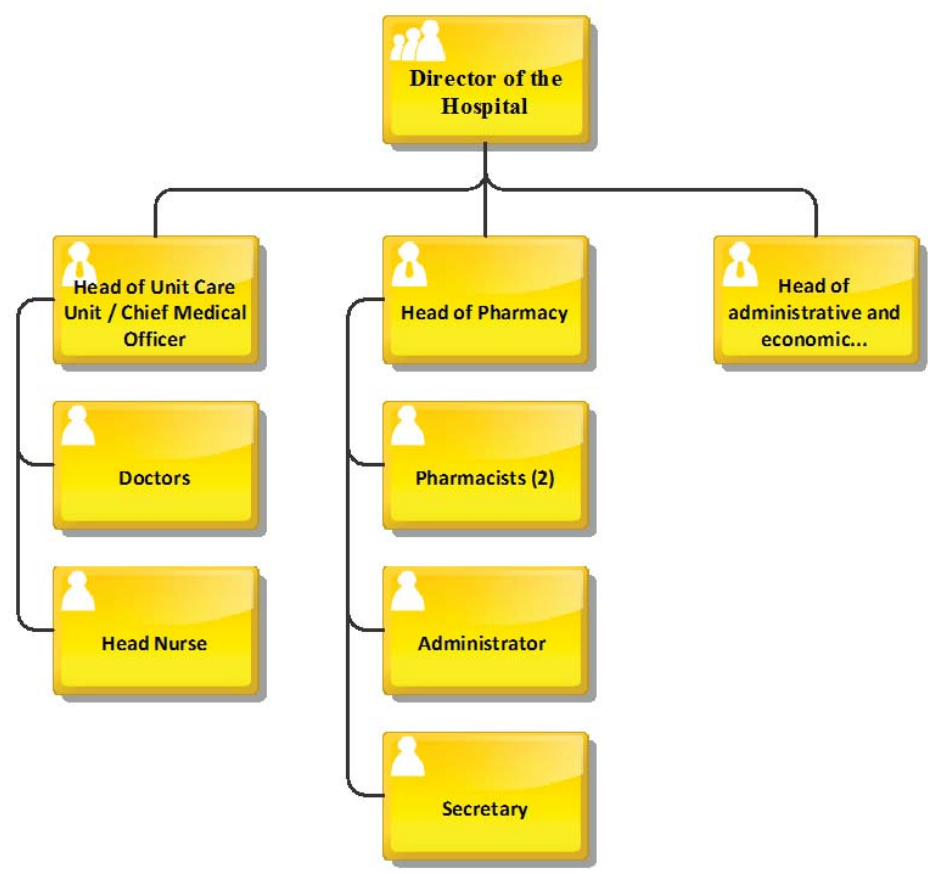

Figure 3: Organization Chart of PLCH Functions

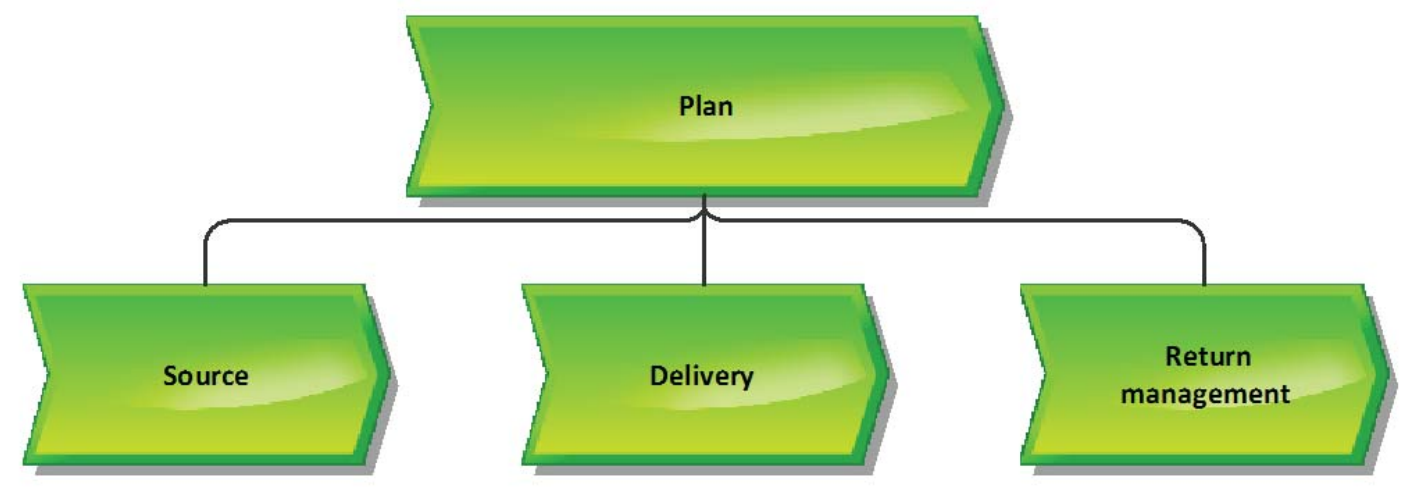

Figure 4: Diagram of value chain[12]

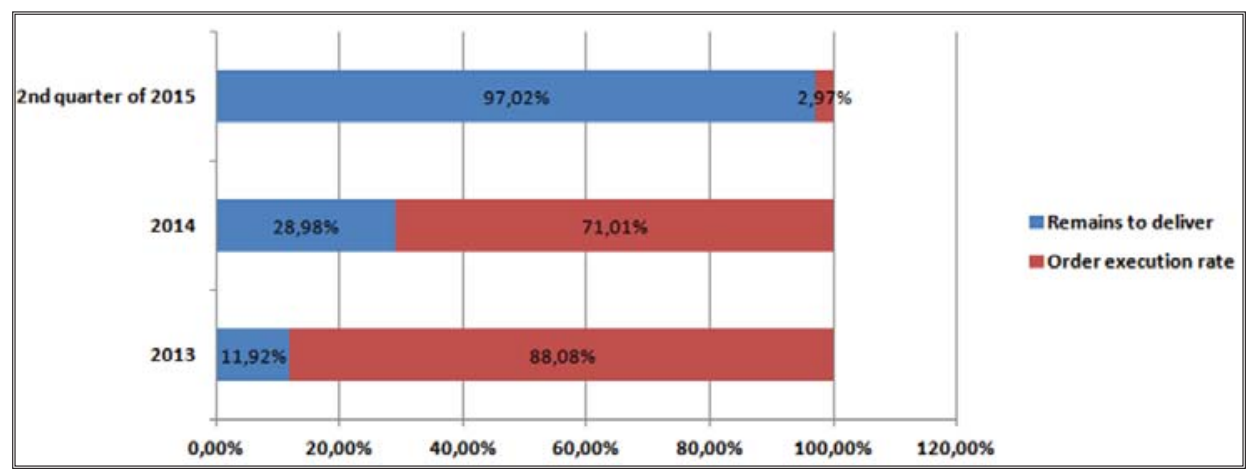

Figure 6: Rate of service of SD at Sidi Lahcen Hospital 


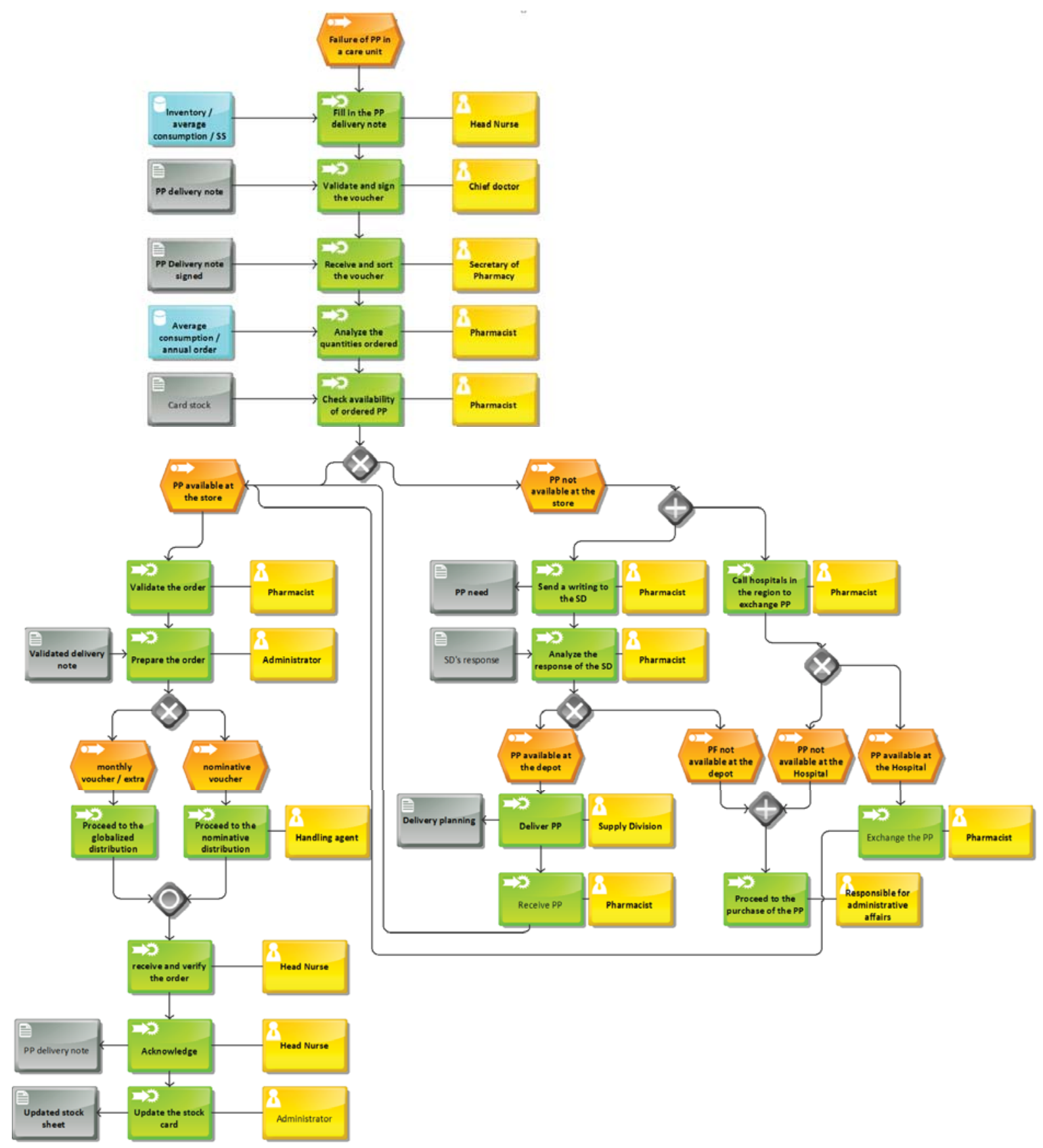

Figure 5: EPC of the process of distribution of PP to care units [13]

\section{CALCULATION OF PERFORMANCE INDICATORS}

\section{$S D$ service rate}

The SD Rate of Service measures the rate of response to annual orders made by the Hospital to the SD. Deliveries being made partially during the year, normally the rate of service target evolves during the year to reach $100 \%$ at the end of the year.

To calculate the service rate of the SD, we refer to the history of the remainder to be delivered since 2013; "Figure 6 " shows the percentage of leftovers to be delivered on $10 / 05 / 2015$ which is $97.02 \%$ or $5,142,537.50 \mathrm{DHs}$. Thus, we note that there are remains to be delivered since 2013 of the order of $11.92 \%$ and 2014 about 29\%. This delay in delivery leads to frequent stockouts and peremptions;

So the service rate of the SD is $88.08 \%$ in $2013,71.01 \%$ in 2014 and $2.97 \%$ as of $05 / 10 / 2015$

\section{Breakdown rate}

We analyzed the inventory records of pharmaceuticals managed by the pharmacy department during the 2014 fiscal year to determine which pharmaceutical products were out of stock. The study showed that 90 pharmaceutical products including 30 medical devices and 60 drugs had a stock-out or $26.7 \%$ of the references ordered by 
the hospital pharmacy. The minimum duration of an out of stock was 6 days, the maximum of 365 days. $60 \%$ of long-term ruptures (more than 90 days) were noted.

So the break-up rate for PP is $26.7 \%$ in 2014 ;

\section{Reliability of stocks}

The concept of stock reliability refers to all existing discrepancies between computerized or administrative stocks and the physical state of stocks;

We used the inventory result from the pharmacy team to determine the percentage of items whose physical inventory is different from the administrative stock.

The result that traces the reliability of the stock is $14.83 \%$ or 50 out of 337 products.

\section{Expiry rate}

The dates of expiry are systematically recorded at the time of receipt on the inventory sheets with the respect of the rule of First Expiration First Out (FEFO) at each exit, When the pharmacy of the hospital cannot consume the articles of which the remaining validity period is lower or equal to 6 months before expiry, she tries to give them away as an exchange or donation.
The analysis of the activity report in 2015 showed that the expiry rate is equal to $0.25 \%$ for drugs, and $1.2 \%$ for medical devices.

So the expiry rate for 2015 is $0.72 \%$;

\section{Replenishment of a care unit}

Monthly orders are developed by service majors. Sometimes there is the dispatch to the pharmacy of urgent orders. These are estimated at about 4 to 5 per month according to the questionnaire sent to the head nurses, especially for the maternity ward, the emergency department and the operating theater.

The Replenishment of a unit of care reflects the number of times / week, the pharmacy replenishes the service units. In our case, it is equal to 1 , ie on average once a week.

\section{Step 3: ANALYZE}

According to Figure 1 and Figure 5, as well as the survey conducted at Sidi Lahcen Hospital, we were able to develop the SWOT matrix to identify the strengths and weaknesses of the FP supply system. one side, as well as the opportunities and threats of this system "Figure 7".

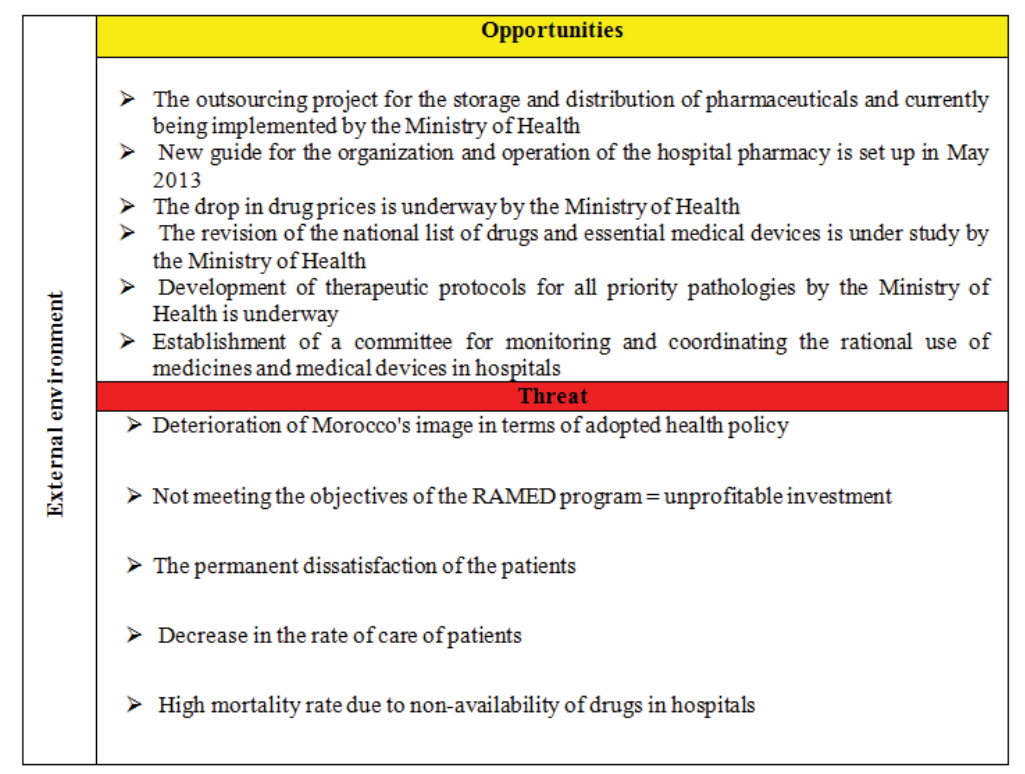

\begin{tabular}{|l|l|}
\hline & Strengths \\
\cline { 2 - 4 } & Inter-hospital exchange: There is a good practice of stock management namely the \\
exchanges between the hospitals between the Rabat Casa axes. The exchange allows the \\
liquidation of medicines whose expiry date is close. Liquidation consists of: redistributing \\
drugs to other care units, finding a hospital that agrees to exchange them for other drugs. If \\
necessary, these medicines can be donated to a hospital. But this practice remains informal, \\
is limited to the initiative of the pharmacist alone and suffers from a lack of logistical \\
means; \\
$>$ The PP delivery note is a stub book to avoid the loss of delivery notes. \\
$>$ Centralization of purchases by the SD allows economies of scale
\end{tabular}

Figure 7: SWOT matrix 


\begin{tabular}{|c|c|c|}
\hline \multirow[b]{2}{*}{ } & & Weaknesses \\
\hline & $\begin{array}{l}0 \\
0 \\
>\end{array}$ & 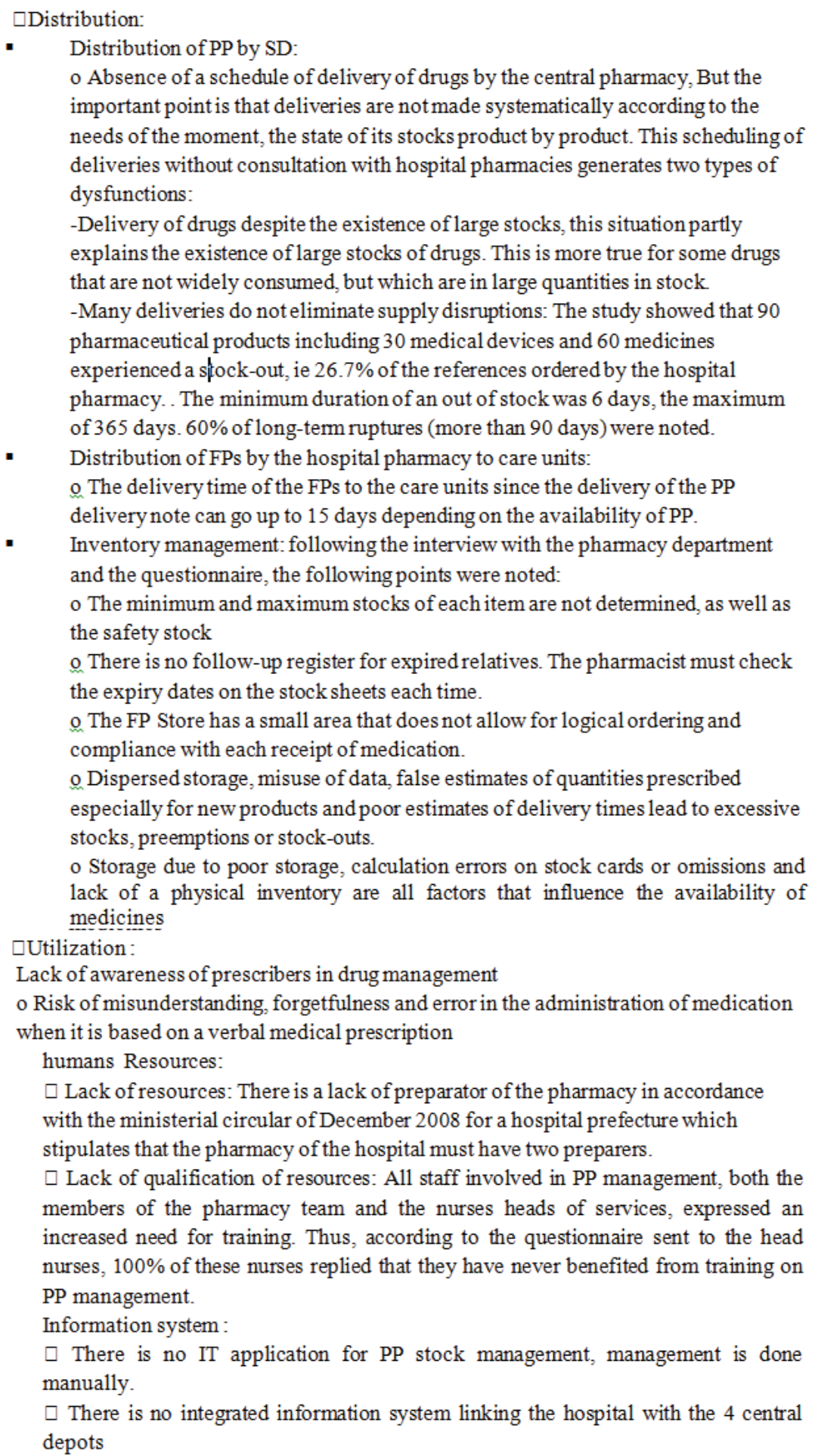 \\
\hline
\end{tabular}

Figure 7: SWOT matrix 


\section{CONCLUSION}

Through this communication, we adopted the most famous Lean Six sigma method, that of the DMAIC method. By following the first 3 steps of this method, we were able to model the PP supply system using the SCOR model, to have a macroscopic view of the system, and then to refine the modeling using the ARIS tool. Then we were able to propose performance indicators that were measured and valued. We then analyzed the system using the SWOT matrix.

In perspective, we will continue the steps of DMAIC to propose actions of improvement, then to make the classification of these actions by the method PROMOTHEE and in the end, to make the simulation of the process of management of the pharmaceutical products to compare the current situation with the optimized one by integrating the proposed improvement solutions.

\section{REFERENCES}

1. Didier, V.C (2014). L'hôpital, une entreprise comme les autres ? Oui, mais .. .7 ème Conférence francophone GISEH Gestion et Ingénierie des Systèmes Hospitaliers, Belgique.

2. Fortineau, V, Lamouri,S, Eckerlein, G (2015). Analyse des potentialités et des limites du LEAN à l'Hôpital: vers une démarche d'excellence hospitalière , QUALITA, Nancy, France.

3. George, M. L (2003). Lean Six Sigma pour les services, McGraw-Hill, Paris.

4. Johnson, C, Shanmugam, R, Roberts, L, Zinkgraf, S, Young, M(2004). Linking Lean Healthcare to Six Sigma : An Emergency Department Case Study, liE Annual Conference.

5. Munro, R. A(2009). Lean Six Sigma for the Healthcare Practice. Milwaakee. ASQ Quality.

6. Arthur, J(2011). Lean Six Sigma for hospitals: Simple steps to fast, affordable, and flawless Healthcare. New York, NY: McGraw-Hill.

7. Carbonneau, C., Benge E., Jaco, M. T., Robinson, M. (2010).A Lean Six Sigma Team Increases Hand Hygiene Compliance and Reduces Hospital-Acquires MRSA Infections by 51\%." Journal for Healthcare Quality 32(4) : 10.2010.

8. Proudlove, N., Moxham, e., Boaden, R. (2010). Lessons for Lean in Healthcare from Using Six Sigma in the NHS, Publie Money \& Management 28(1),pp.2734,DOI:10.1111/j.14679302.2008.00615.x.

9. Snee, R.D.(2010). Lean Six Sigma-getting better all the time. International Journal of Lean Six Sigma, Vol. 1 Issue: 1, pp.9-29 ,DOI : 10.1108/20401461011033130.
10. Niemeijer,G.C, Trip ,A., Ahaus, K.T, Does, R.J, Wendt, K.W.(2010) Quality in trauma care: Improving the discharge procedure of patients by means of Lean Six Sigma. Journal of Trauma and Acute Care Surgery, 69(3), pp.614-619, DOI: 10.1097/ TA.0b013e3181e70f90.

11. Dumoulin J(2006). Analyse du système d'approvisionnement au Maroc : l'expérience de regroupement des achats depuis 2001, Missions OMS, HALSHS-00104206, version1.

12. TADLAOUI, K, CHAFI, A, ENNADI, A (2016).Modélisation du système d'approvisionnement des produits pharmaceutiques au sein d'un hôpital public. 3ème édition du Colloque International sur le Monitoring des Systèmes Industriels CIMSI.
Paper submitted: 28.11.2017.

Paper accepted: 08.02.2018.

This is an open access article distributed under the CC BY-NC-ND 4.0 terms and conditions. 